\title{
Protective Effect of Costus Speciosus Rhizome Extract Against Cytotoxicity Induced by Tramadol in Mice
}

\author{
Hamid M. A. Daabo ${ }^{1, *(1)}$ \\ 1 Pharmacy Department, Duhok Technical Institute, Duhok Polytechnic University, Duhok, Iraq \\ * Correspondence: hamed.abdullah@dpu.edu.krd;
}

Scopus Author ID 57195330987

Received: 20.08.2020; Revised: 9.09.2020; Accepted: 11.09.2020; Published: 13.09.2020

\begin{abstract}
Tramadol is a centrally acting analgesic generally used to treat moderate to severe pain. This study was designed to evaluate the protective effect of Costus speciosus rhizome extract (CSRE) against the chromosomal 'aberration's tramadol-induced in mice bone marrow. Sixty male albino mice were examined in this study and separated into four groups which are as follows: Control group; CSRE group (which have been supplied with $200 \mathrm{mg} / \mathrm{kg}$ per day); Tramadol group (Supplied with $40 \mathrm{mg} / \mathrm{kg}$ ); and CSRE + Tramadol group ( which were given Tramadol for a period of 4 weeks and then given CSRE for a further 4 weeks, applying the same dosage. Microscopic examination of the bone marrow showed a significant increase in structural chromosomal aberrations (centromeric attenuation, gap chromosome, ring chromosome, end to end association, and centric fusion) in addition to numerical chromosomal aberrations (polyploidy and endomitosis) in the treated mice with Tramadol comparable to mice in the control group. The administration of Tramadol disrupted oxidants-antioxidants balance, which is proven by the increased malondialdehyde (MDA) and the reduced superoxide dismutase (SOD), catalase (CAT), and glutathione (GSH). Interestingly, in contrast, CSRE administration has shown attenuate in the numerical chromosomal aberrations and biochemical modification caused by Tramadol. This study demonstrated that CSRE supplementation is improved the tramadol-induced cytotoxicity injury through its antioxidant activity.
\end{abstract}

Keywords: chromosomal aberrations; costus; antioxidants; Tramadol; mice.

(c) 2020 by the authors. This article is an open-access article distributed under the terms and conditions of the Creative Commons Attribution (CC BY) license (https://creativecommons.org/licenses/by/4.0/).

\section{Introduction}

Chromosomal aberrations can occur due to the treatment with some drugs such as opiates, which leads to deletion and/or addition in the chromosomes [1]. Consequently, change in the sequence number of genes in the chromosomes [2]. Analgesics such as opioids are usually used for treating chronic and severe pains [3-6]. Tramadol is widely used to treat moderate and severe pain [7]. It has been reported that Tramadol delivers its action through reuptake inhibition of serotonin and noradrenaline neurotransmitters and weak binding to $\mu$ opiate receptors, which is regarded as a dual mechanism of action $[3,5,7]$. In addition, the metabolism of Tramadol in the liver founded leads to increased oxidative stress caused by the free radicals $[1,3,8]$. Similar to other opioids, free radical tramadolinduced lead to DNA injury is produced by reactive oxygen species (ROS) [8-10]. However, the toxicity of Tramadol has been investigated in; liver [11], kidney [12], brain, and testes $[3,13,14]$. Recent studies have shown that cytotoxicity tramadol-induced causes 
damages of the lysosomal membrane, the release of DNA endonucleases, and mitochondrial impairment function $[5,10,15]$.

Also, in another study, cytotoxicity tramadol-induced has been proven to encourage chromosomal aberrations in the bone marrow of mice [9]. Tramadol metabolism increases the oxidative stress levels in the tissue as a result of the accumulating of ROS $[11,16]$; therefore, it induces different cytotoxic effects [17]. Whereas disturbance, the production of ROS reduces to detoxify of ROS, which consequently causes induced oxidative stress $[18,19]$. Herbal medicines detoxify these ROS via their antioxidant capacities [20-22]. Previously, it has been reported a relation between ROS enhancement and the total polyphenols and flavonoid compounds in the medicinal plants [23,24].

The pharmacological effects of natural compounds in attenuating toxicity effects of Tramadol in different organs have been demonstrated in the experimental animals [19,2528]. CSRE is a medicinal plant referred to as spiral ginger or crepe ginger [29]. It is grown in the south of India and is used for treating several diseases [30]. Dried powder of the costus uses for treatment against several diseases such as arthritis [31-34], wounds, constipation, leprosy, asthma, inflammations, [35], and anemia [36]. There are numerous useful biological and pharmacological activities such as: antioxidant [37], anti-tumor [38], anti-inflammatory [39], anti-apoptotic [40], and pancreas-protective, which CSRE possess [41] CSRE is rich in polyphenols and flavonoid compounds, and it has been recorded that the CSRE is able to protect the cells from the harmful effect of reactive oxidative species (ROS) through preventing the establishment of these species in the cells [23,42]. So, the current study was planned to assess the protective role of CSRE against structural chromosomal aberrations induced by Tramadol through assessing the oxidative status in the bone marrow of mice.

\section{Materials and Methods}

\subsection{Experimental animals.}

The experimental animals used in this study consisted of sixty male albino mice (10 weeks old, 40-50 g). These animals were acquired from the animal house of the central public laboratory of Duhok city, Duhok, Iraq. The mice were contained in cages exposed to 12 hours of light/dark environmental consistency; the mice were fed with laboratory nourishments and water on a daily basis for a one-week period before commencing the acclimatization experiment.

\subsection{Experiment design.}

The design of the experiment consisted of 60 mice in total, which were divided into 4 groups (15 mice per group). The four groups were identified as follows: the control group, the CSRE group, the tramadol group, and the tramadol + CSRE group. Each group was to be treated with a substance, on a daily basis, for a period of 4 weeks. The control group was orally treated with physiological saline $(0.9 \% \mathrm{NaCl})$. The CSRE group were administered with CSRE ( $200 \mathrm{mg} / \mathrm{kg}$ per day) orally, as implemented by Al-brakati, Belal, and Alsbery [41]. The tramadol mice group was given Tramadol $(40 \mathrm{mg} / \mathrm{kg})$ orally, inaccordance with Albarakai, and Alsbery [11]. The mice in Tramadol + CSRE group were orally administrated with Tramadol, at first, then after $3 \mathrm{~h}$, they're administrated with CSRE; the dosage for this group was the same as the CSRE group and the tramadol group. 


\subsection{Preparation of crude extract.}

Costus speciosus rhizomes were purchased from the local perfumery market in Duhok, Iraq. The species was identified and authenticated by the central public laboratory of Duhok city. CSRE was prepared based on the method described by Thabit [29]. All chemicals and biochemicals were obtained from Sigma Chemical Company (St. Louis, MO, USA).

\subsection{Metaphase scoring.}

For chromosomal aberrations analysis, each mouse was injected with $0.5 \mathrm{mg} / \mathrm{kg}$ colchicine 2 hours before the killing. The bone marrow was immediately extracted from the femur and then processed for the staining process in the Giemsa stain. Microscopic examination was performed for chromosomal aberrations on 50 metaphases spread per each animal; afterward, the well-spread chromosomes were chosen for scoring. Examination for structural and numerical aberration was done on all metaphase spreads based on the technique described by Kilian et al. [43].

\subsection{Mitotic index.}

The number of dividing cells (3000 cells/animal), which was including the late prophases and the metaphases, were counted. The number of dividing cells/1000/animal was used to calculate the mitotic index. The mitotic index was calculated as the number of dividing cells /1000 cell/animal, as described by Kilian, Moreland, Benge, Legator, and Whorton [43].

\subsection{Oxidant/antioxidant status analysis.}

In order to estimate lipid peroxidation, the estimation of malondialdehyde was performed as an index, according to Ohkawa et al. protocol [44]. The activity of Bone marrow superoxide dismutase was achieved according to the method of Kovárová, et al. [45]. The activity of catalase was carried out according to the procedures described by Aebi [46] by evaluating the decomposition of hydrogen peroxide at $240 \mathrm{~nm}$. At the same time, a reduced level of glutathione in the homogenates of bone marrow was estimated according to Ellman's technique [47]36].

\subsection{Statistical analysis.}

Statistical analysis was carried out using one-way analysis of variance (ANOVA), the significance between groups analyzed by Tukey's post hoc test using SPSS version 17 computer software. $\mathrm{p}<0.05$ were considered statistically significant.

\section{Results}

\subsection{Chromosomal aberrations.}

The microscopic observation of this study showed the normal distribution of chromosomes mice of the control group, structural and numerical chromosomal aberrations in mice of the tramadol group, and the chromosomes in mice of the CSRE group, as seen in figure 1. The analectic result of this study showed a significant increased $(p<0.05)$ in all the structural chromosomal aberrations (chromatid breakage, centromeric attenuation, 
centric fusion, ring chromosome, and an end to end association) and numerical chromosomal aberrations (endomitosis and polyploidy) in mice of the treated group with Tramadol when compared with the control group. In contrast, the treated mice with CSRE and then Tramadol were discovered to reduce the changes in all the structural and numerical chromosomal aberrations as compared to the Tramadol treated group. However, this reduction still non-significant values when compared with the control groups, as seen in tables 1 and 2, and in figures 1 and 2-this result was reflecting the cytoprotective role of CSRE against tramadol-induced structural and numerical chromosomal aberrations injury.

\subsection{Mitotic index.}

The mitotic index analysis in this study showed a non-significant values numbers of the metaphase cells per metaphase cell in the mice when compared to the number of metaphase in all the groups, as seen in figure 3. These results indicated well-spread metaphases for each cell in mice of all the groups.

1

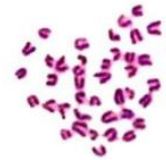

4

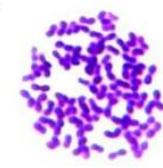

7

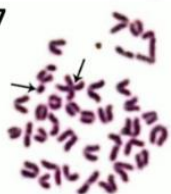

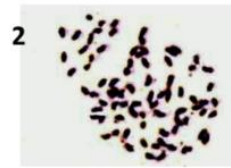

5

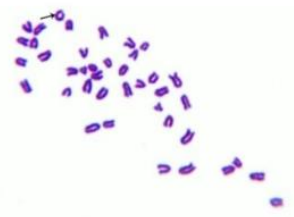

8

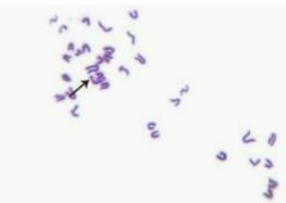

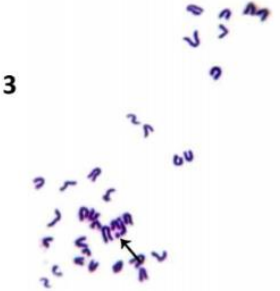

6

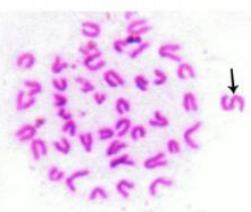

Figure 1. A photomicrograph of metaphase spreading from mouse bone marrow shows normal chromosomes (1), centromeric attenuation (2), gap chromosome (arrow) (3), polyploidy with endomitosis (4), ring chromosome (arrow) (5), end to end association (6), centric fusion (7) and chromatid breakage (8).

Table 1. Showing analysis structural chromosomal aberrations induced in mice bone marrow cells in all the groups.

\begin{tabular}{c|c|c|c|c}
$\begin{array}{c}\text { Type of } \\
\text { aberration }\end{array}$ & Control group & CSRE group & Tramadol group & $\begin{array}{c}\text { Tramadol + CSRE } \\
\text { group }\end{array}$ \\
\hline $\begin{array}{c}\text { Gap } \\
\begin{array}{c}\text { Centromeric } \\
\text { attenuation }\end{array}\end{array}$ & $2.6 \pm 0.6$ & $2.5 \pm 0.3$ & $5.3 \pm 0.2^{*}$ & $3.1 \pm 0.2$ \\
\hline Centric fusion & $2.7 \pm 0.3$ & $2.5 \pm 0.6$ & $5.4 \pm 0.6^{*}$ & $3.3 \pm 0.5$ \\
\hline $\begin{array}{c}\text { Ring } \\
\text { chromosome }\end{array}$ & $2.4 \pm 0.3$ & $2.2 \pm 0.3$ & $4.9 \pm 0.3 *$ & $3 \pm 0.4$ \\
\hline $\begin{array}{c}\text { End to end } \\
\text { association }\end{array}$ & $2.5 \pm 0.1$ & $2.3 \pm 0.2$ & $5.4 \pm 0.2^{*}$ & $2.9 \pm 0.1$ \\
\hline
\end{tabular}

Data are expressed as Mean \pm S.E, $n=15$. $* P<0.05$ 


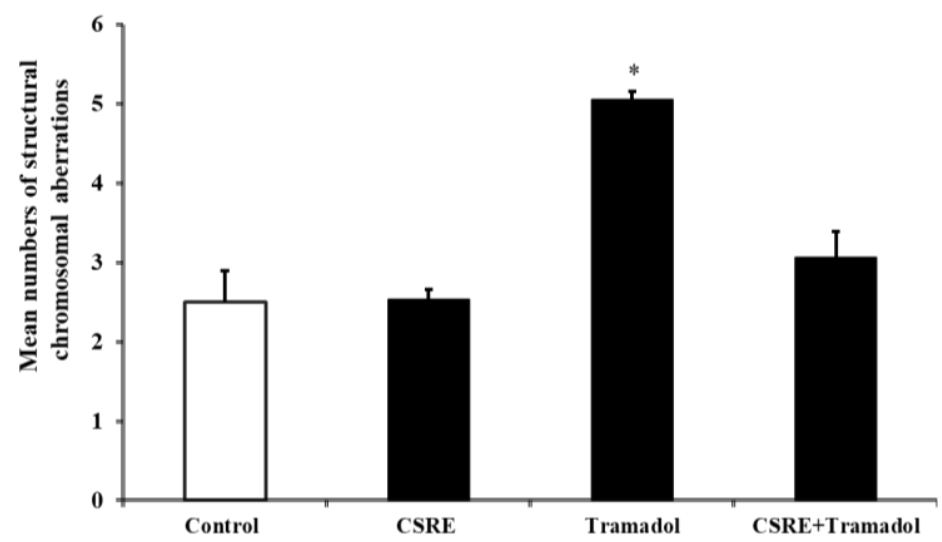

Figure 2. Comparing mean numbers of structural chromosomal aberrations in all the groups, Data are expressed as Mean \pm S.E., $n=15$. $* \mathrm{P}<0.05$.

Table 2. Showing analysis numerical chromosomal aberrations induced in mice bone marrow cells marrow in all the groups.

\begin{tabular}{c|c|c|c|c}
$\begin{array}{c}\text { Type of } \\
\text { aberration }\end{array}$ & Control group & CSRE group & $\begin{array}{c}\text { Tramadol } \\
\text { group }\end{array}$ & $\begin{array}{c}\text { Tramadol + CSRE } \\
\text { group }\end{array}$ \\
\hline Endomitosis & $1.3 \pm 0.2$ & $1.1 \pm 0.4$ & $4.7 \pm 0.2^{*}$ & $1.8 \pm 0.4$ \\
\hline Polyploidy & $1.2 \pm 0.1$ & $1.4 \pm 0.4$ & $4.1 \pm 0.7^{*}$ & $1.6 \pm 0.2$
\end{tabular}

Data are expressed as Mean \pm S.E, $n=15$. $* \mathrm{P}<0.05$.

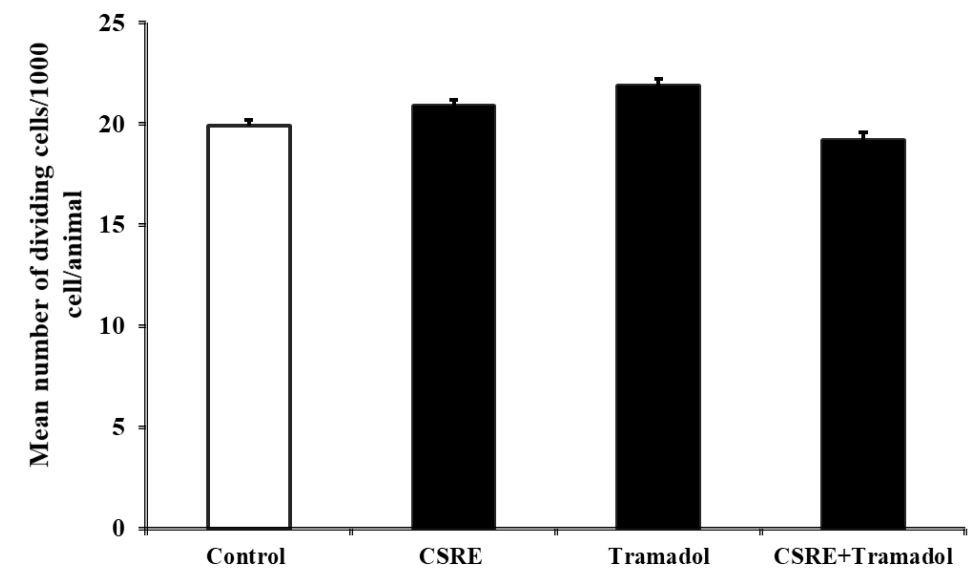

Figure 3. Showing the mean number of the mitotic index of mice bone marrow cells in all the groups. Data are expressed as Mean \pm S.E., $n=15$. $* \mathrm{P}<0.05$.

\subsection{Antioxidants and lipid peroxidation markers results.}

The obtained findings in figure 5 revealed that the disturbance in the oxidative conditions was instigated by the tramadol administration. Tramadol caused a significant increase to $(\mathrm{p}<0.05)$ to the malondialdehyde level (figure $4 \mathrm{~A})$ and deactivated superoxide dismutase (figure $4 \mathrm{~B}$ ) and catalase (figure $4 \mathrm{C}$ ) and decreased glutathione content (figure 4 D) comparing with the control group. Thus far, the mice within the CSRE + Tramadol group were found to lessen the changes in the oxidative stress biomarkers, in addition, to improve the activity of antioxidant enzymes compared to the Tramadol treated group. But still, no significant values when compared with the control group.

\subsection{Discussion.}

Tramadol is a narcotic drug used to treat moderate to severe pain $[5,48]$. Although the toxicological and histopathological damages tramadol-induced have been recorded in 
several experimental 'animal's models [3,13,14]. Earlier studies have reported that the use of Tramadol for a long period leads to disrupted oxidant/antioxidant levels [49,50].

A

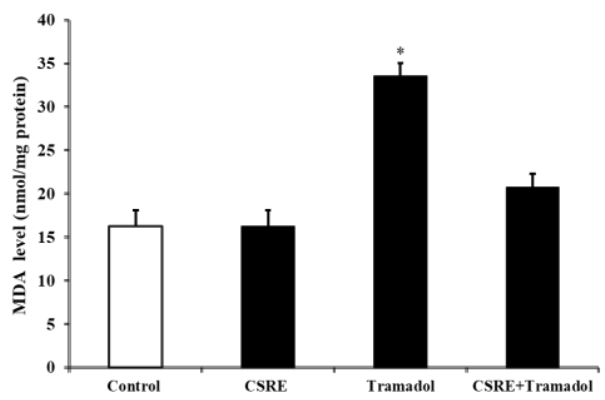

D

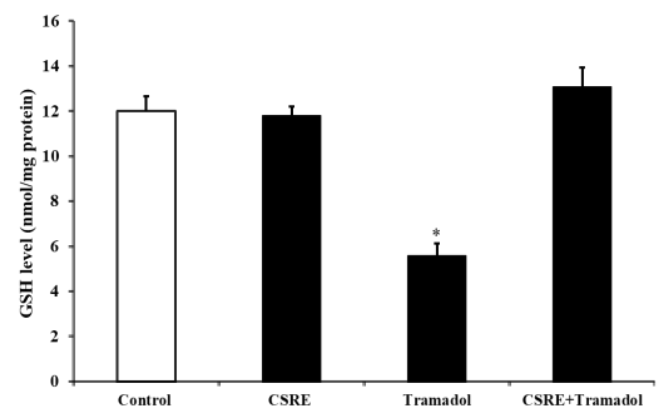

B

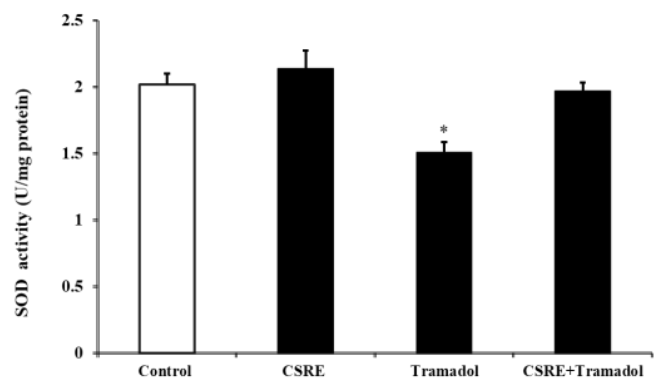

C

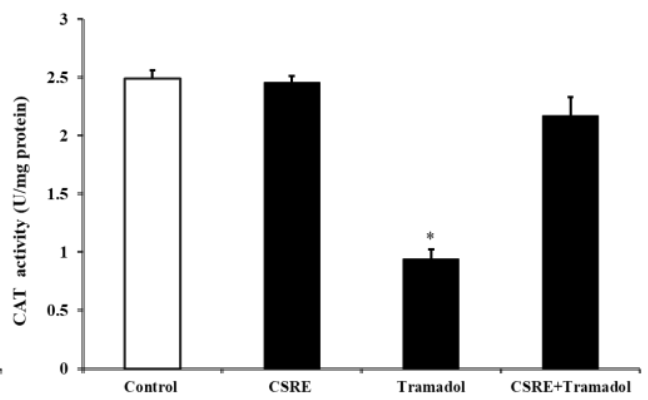

Figure 4. Oxidant and antioxidant markers of mice bone marrow cells in the control group, CSRE group, tramadol group, and CSRE + Tramadol group. Data are expressed as Mean \pm S.E., $n=15 . * P<0.05$.

Also, as a consequence of long term tramadol use, it can lead to an increase of lipid peroxidation levels and reduction of antioxidant levels [51,52]. In this regard, it has been reported that the treatment tramadol with low doses leads to induce chromosomal aberrations in mice bone marrow [9,53]. The aim of this study was to emphasize the potential protecting role of CSRE against tramadol-induced the structural and numerical chromosomal aberrations in mice through evaluating chromosomal aberrations changes and some oxidative stress biomarkers.

The results of this study showed increased structural and numerical chromosomal aberrations in the treated mice with Tramadol as compared with control animals. The significant chromosomal aberrations were noticed primarily in the chromatid breakages (deletion, gap, break, and fragments) form. Chromatid lesions, and subsequently, chromatid breakage, has been reported occurred as a result of chromosomes damage after the G1 stage of the cell cycle $[54,55]$. Thus, it could be conceivable to demonstrate that Tramadol employs its clastogenic effect on the cell cycle after the G1 stage. Also, the number of cells with end to end associations, centromeric attenuation, centric fusion, and ring chromosome increased significantly in the tramadol group. Accordingly, this type of aberration indicated damages in sister chromatid exchanges in the chromosomes as a result of the cumulative effect of Tramadol on mice in the tramadol group. Centromeric attenuation, for example, splitting of the centromere without mitosis, might be considered as an early stage of endomitosis and promotes an increase of polyploidy [56,57]. The results obtained in this study demonstrated a significate increase in the level of polyploidy; the centromeric attenuation is, therefore, most likely an expression of the cytotoxicity. Moreover, It has been established that polyploidy could result from disturbance of the spindle apparatus [1]. 
Furthermore, current findings showed an elevation in polyploid cell number, which could be proof of interaction between Tramadol and the spindle apparatus. Previous studies have reported that the Tramadol could induce apoptosis in the experimental models [11], and it induces growth and development of cancer [58]. Safa Faraj [59] reported that there is no mentioned modulation that occurs in the sister chromatid exchange levels when treated for two weeks with a therapeutic dose of Tramadol, nor before neither after treatment. Whereas, in vitro and in vivo studies applied on human lymphocytes showed that treatment of these cells with Tramadol for two weeks induced a frequency in sister chromatid exchange. A current study reported that there is a significant increase in chromosome breakages in mice after four weeks treatment with Tramadol $(40 \mathrm{mg} / \mathrm{kg})$, which is consistent with previous studies those reported that the mechanism of formation of sister chromatid exchange is different from that of chromosome aberrations since the sister chromatid exchange represents only a part of the total DNA damage [60,61]. In the current study, significant changes in the mitotic were observed in the treated group with Tramadol, which could be an indicator of interaction between Tramadol with the spindle apparatus. Recent studies showed a deleterious effect of chromosomal aberrations on the cells and could result in cell damage $[1,8,15]$. It has been reported that aberrations such as translocations and inversions could be lead to modify the faction of gene function deprived of associated loss in cell viability [62]. Occurring of alternation in gene function could be a response to numerous different types of cancer [63], demonstrating the possible participation of chromosomal aberrations in carcinogenesis. Duly, several well-known metagenes and/or carcinogens can induce chromosomal aberrations [64]. Accordingly, analysis of chromosomal aberration regarding as a valuable genotoxic/cytotoxic indicator in bone marrow cells subsequent to exposures to xenobiotics in vivo. The findings in this study may indicate how Tramadol affects clastogenic by inducing cytogenetic changes. These results correspond with Maleek, Safaa, and Marwa [62], who showed that the chromosomal aberrations and micronuclei accompanied with a reduction in the mitotic index in rats following the treatments with Tramadol and/or dactinomycin alone and tramadol/dactinomycin combination, compared to control groups. Similar results have been reported by Ali, Rafiq, Mubarik, Zahoor, Asad, Yaqoob, Ahmad, and Qamar [2], who concluded that tramadol cause genotoxicity in mice and that is dose-dependent and has low repair capability.

It is known that opioids-induced organ toxicity could result from oxidative stress implication [49,50]. Malondialdehyde is the most important oxidation produced results from lipid peroxidation, which is regarded as a significant factor used to estimate the amount of lipid peroxidation in bone marrow [65]. The increment in of malondialdehyde level results from the ability of the tramadol compounds to stimulate ROS and peroxide radicals, which compliments the peroxidation of membrane lipids and exponentially raises malondialdehyde amounts [66]. Moreover, the reduced level of glutathione in this study is possibly directly influenced by the fact of the conjugation of glutathione with tramadol metabolites aiming to detoxify the cellular effect of these metabolites and also to impede the high level of malondialdehyde [67]. Furthermore, the decrease in catalase and superoxide dismutase is more likely because of the excess pro malondialdehyde duction of ROS, which ultimately influences approximately wholly bio-macromolecules, leading to numerous cellular adverse reactions. It has been reported that the administration of Tramadol enhances the production of ROS, which may also cause interruption of the gene 
expression of these antioxidant enzymes, which perfectly illustrate the decrease of its activity [2]. Naturally extracted Antioxidants products have been found to eradicate the progress of oxidative stress that resulted from the administration of the narcotic drugs, including tramadol [68]. Astonishingly, the current finding of this study has exposed that tramadol intoxication produced a magnificent growth in malondialdehyde along with the deactivation of superoxide dismutase and catalase. Conversely, co-administrated of CSRE following tramadol administration shows the ability of CSRE in restoring the levels of antioxidant enzymes and inhibiting the peroxidation of lipids. Consequently, lead to a decreased in the structural and numerical chromosomal aberrations of the bone marrow. The outcome of this might be indicated by the antioxidant activity of the polyphenols and flavonoid compounds in CSRE, which have the ability to scavenge reactive oxygen species [29]. These results are partially agreed with the results of Ezejiofor and Orisakwe [69], who found that administration of the aqueous leaves extract of Costus as an antioxidant led to inhibit the oxidative stress and histopathological changes induced by lead in the testicular tissue of rats.

\section{Conclusion}

Results of the current study showed that tramadol-induced structural and numerical chromosomal aberrations, as evidenced by the disturbance in the oxidative status (increasing malondialdehyde and decreasing superoxide dismutase, catalase, and glutathione). In contrast, CSRE co-administered, along with Tramadol, reduced the chromosomal aberrations. In other words, due to the antioxidant activity of CSRE it is wise to use the CSRE during the Tramadol administration course in order to decrease tramadolinduced chromosomal aberrations. These conclusive verdicts allude that CSRE is utilized to decrease tramadol-induced chromosomal aberrations through its antioxidant activity.

\section{Funding}

This research received no external funding.

\section{Acknowledgments}

This research has no acknowledgment.

\section{Conflicts of Interest}

The authors declare no conflict of interest.

\section{References}

1. Dkhil, M.A.; Tohamy, A.; Gabry, M.S. Chromosomal aberrations induced in bone marrow cells of mice due to the administration of the non-steroidal anti-inflammatory drug, Piroxicam. African Journal of Pharmacy and Pharmacology 2009, 5, 93-103, https://doi.org/10.5897/AJPP10.267.

2. Ali, T.; Rafiq, M.; Mubarik, M.S.; Zahoor, K.; Asad, F.; Yaqoob, S.; Ahmad, S.; Qamar, S. Genotoxicity and repair capability of Mus musculus DNA following the oral exposure to Tramadol. Saudi Journal of Biological Sciences 2020, 27, 12-17, https://doi.org/10.1016/j.sjbs.2019.03.008.

3. Ahmed, M.A.; Kurkar, A. Effects of opioid (tramadol) treatment on testicular functions in adult male rats: The role of nitric oxide and oxidative stress. Clinical and experimental pharmacology \& physiology 2014, 41, 317-323, https://doi.org/10.1111/1440-1681.12213.

4. Lehmann, K.A. Tramadol in acute pain. Drugs 1997, 53 Suppl 2, 25-33, https://doi.org/10.2165/00003495-199700532-00007. 
5. Schnabel, A.; Reichl, S.U.; Meyer-Friessem, C.; Zahn, P.K.; Pogatzki-Zahn, E. Tramadol for postoperative pain treatment in children. The Cochrane database of systematic reviews 2015, 2015 , https://doi.org/10.1002/14651858.CD009574.pub2.

6. Mallick-Searle, T. Commonly used nonopioid analgesics in adults. The Peer-Reviewed Journal of Clinical Excellence 2018, 48, 61-63, https://doi.org/10.1097/01.NURSE.0000530985.53988.37.

7. Lee, C.R.; McTavish, D.; Sorkin, E.M. Tramadol. A preliminary review of its pharmacodynamic and pharmacokinetic properties, and therapeutic potential in acute and chronic pain states. Drugs 1993, 46, 313-340, https://doi.org/10.2165/00003495-199346020-00008.

8. Cavallo, D.; Ursini, C.L.; Bavazzano, P.; Cassinelli, C.; Frattini, A.; Perniconi, B.; Di Francesco, A.; Ciervo, A.; Rondinone, B.; Iavicoli, S. Sister chromatid exchange and oxidative DNA damage in paving workers exposed to PAHs. The Annals of occupational hygiene 2006, 50, 211-218, https://doi.org/10.1093/annhyg/mei072.

9. Maleek, M.I.; Faraj, S.A.; Khalaf, M.M. Genotoxicity of Dactinomycin and Tramadol on Mice Bone Marrow. International Journal of Scientific Engineering and Research (IJSER) 2015, 79, 2347-3878.

10. Puli, L.K.; Patil, P. Genotoxic evaluation of morphine, buprenorphine, pentazocine, and noscapine by micronucleus and comet assay in albino mice. Indian Journal of Pharmacology 2007, 39, https://doi.org/10.4103/0253-7613.39144.

11. Albarakai, A.Y.; Alsbery, H.M.A.E. Evaluation of the Hepatoprotective Efficacy of Moringa oleifera on Tramal-Induced Liver Toxicity in Animal Modules. Research Journal Of Pharmaceutical Biological And Chemical Sciences 2016, 7, 1494-1501.

12. Al-Brakati, A. Protective Effect of Moringa Oleifera Leaves Against Tramadol-Induced Nephrotoxicity in Mice. International Journal of Toxicological and Pharmacological Research 2017, 9, 156-162, https://doi.org/10.25258/ijtpr.v9i02.9053.

13. Atici, S.; Cinel, L.; Cinel, I.; Doruk, N.; Aktekin, M.; Akca, A.; Camdeviren, H.; Oral, U. Opioid neurotoxicity: comparison of morphine and Tramadol in an experimental rat model. The International journal of neuroscience 2004, 114, 1001-1011, https://doi.org/10.1080/00207450490461314.

14. Atici, S.; Cinel, I.; Cinel, L.; Doruk, N.; Eskandari, G.; Oral, U. Liver and kidney toxicity in chronic use of opioids: an experimental long term treatment model. Journal of biosciences 2005, 30, 245-252, https://doi.org/10.1007/BF02703705.

15. Galloway, S.M. Cytotoxicity and chromosome aberrations in vitro: experience in industry and the case for an upper limit on toxicity in the aberration assay. Environmental and molecular mutagenesis 2000, 35, 191-201, https://doi.org/10.1002/(SICI)1098-2280(2000)35:3<191::AID-EM6>3.0.CO;2-4.

16. Sheweita, S.A.; Almasmari, A.A.; El-Banna, S.G. Tramadol-induced hepato-and nephrotoxicity in rats: Role of Curcumin and Gallic acid as antioxidants. PloS one 2018, 13, https://doi.org/10.1371/journal.pone.0202110.

17. Yu, H.-S.; Oyama, T.; Isse, T.; Kitagawa, K.; Tanaka, M.; Kawamoto, T. Formation of acetaldehydederived DNA adducts due to alcohol exposure. Chemico-biological interactions 2010, 188, 367-375, https://doi.org/10.1016/j.cbi.2010.08.005.

18. Al-Brakati, A.; Kassab, R.; Lokman, M.; Elmahallawy, E.; Amin, H.; Abdel Moneim, A. Role of thymoquinone and ebselen in the prevention of sodium arsenite-induced nephrotoxicity in female rats. Human \& experimental toxicology 2019, 38, 482-493, https://doi.org/10.1177/0960327118818246.

19. Yin, M.; Jiang, N.; Guo, L.; Ni, Z.; Al-Brakati, A.Y.; Othman, M.S.; Moneim, A.E.A.; Kassab, R.B. Oleuropein suppresses oxidative, inflammatory, and apoptotic responses following glycerol-induced acute kidney injury in rats. Life sciences 2019, 232, https://doi.org/10.1016/j.lfs.2019.116634.

20. Santos-Sánchez, N.F.; Salas-Coronado, R.; Villanueva-Cañongo, C.; Hernández-Carlos, B. Antioxidant compounds and their antioxidant mechanism. In: Antioxidants. IntechOpen: 2019; https://doi.org/10.5772/intechopen.85270.

21. Hrelia, S.; Angeloni, C. New Mechanisms of Action of Natural Antioxidants in Health and Disease. Multidisciplinary Digital Publishing Institute 2020, 9, https://doi.org/10.3390/antiox9040344.

22. Mbah, C.; Orabueze, I.; Okorie, N. Antioxidants Properties of Natural and Synthetic Chemical Compounds: Therapeutic Effects on Biological Systems. Acta Scientific Pharmaceutical Sciences 2019, 3, 28-42, https://doi.org/10.31080/ASPS.2019.03.0273.

23. Al-Brakati, A. Protective effect of aged garlic extracts against hepatotoxicity induced by ethephon in Wistar albino rat. Environmental Science and Pollution Research 2020, 27, 6139-6147. https://doi.org/10.1007/s11356-019-07148-w.

24. Bouterfas, K.; Mehdadi, Z.; Elaoufi, M.; Latreche, A.; Benchiha, W. Antioxidant activity and total phenolic and flavonoids content variations of leaves extracts of white Horehound (Marrubium vulgare Linné) from three geographical origins. Annales pharmaceutiques francaises 2016, 74, 453-462, https://doi.org/10.1016/j.pharma.2016.07.002.

25. Mohamed, H.M.; Mahmoud, A.M. Chronic exposure to the opioid Tramadol induces oxidative damage, inflammation and apoptosis, and alters cerebral monoamine neurotransmitters in rats. Biomedicine \& Pharmacotherapy 2019, 110, 239-247, https://doi.org/10.1016/j.biopha.2018.11.141. 
26. Hassan, A.; Ullah, H.; Israr, M. The antioxidant activity and phytochemical analysis of medicinal plant. $\begin{array}{llllll}\text { Veronica biloba. Lett Appl NanoBioScience } & \mathbf{2 0 1 9}, & 8, & \text { 732-738, }\end{array}$ https://doi.org/10.33263/LIANBS84.732738.

27. Al-Brakati, A.Y.; Fouda, M.S.; Tharwat, A.M.; Elmahallawy, E.K.; Kassab, R.B.; Moneim, A.E.A. The protective efficacy of soursop fruit extract against hepatic injury associated with acetaminophen exposure is mediated through antioxidant, anti-inflammatory, and anti-apoptotic activities. Environmental Science and Pollution Research 2019, 26, 13539-13550, https://doi.org/10.1007/s11356-019-04935-3.

28. Subedi, M.; Bajaj, S.; Kumar, M.S.; Mayur, Y. An overview of Tramadol and its usage in pain management and future perspective. Biomedicine \& Pharmacotherapy 2019, 111, 443-451, https://doi.org/10.1016/j.biopha.2018.12.085.

29. Thabit, Z.A. Evaluation of some bioactive effect of phenolic compounds in Costus speciosus rhizome extract. Iraqi Journal of Science 2018, 59, 38-43, https://doi.org/10.24996/ijs.2018.59.1A.6.

30. Ammal, J.; Prasad, N. Ethnobotanical finding on Costus speciosus (Koen) sm. Among the Kannikkars of Tamil Nadu. J Econ Tax Bot 1984, 5, 129-133.

31. Ariharan, V.; Devi, V.M.; Rajakokhila, M.; Prasad, P.N. Antibacterial activity of Costus speciosus rhizome extract on some pathogenic bacteria. International journal of advanced life sciences 2012, 4, 24-27.

32. Chaturvedi, D. Recent developments in the anti-inflammatory potential of sesquiterpene lactones and their semisynthetic analogs. In: Discovery and Development of Anti-Inflammatory Agents from Natural Products. Elsevier: 2019; pp. 185-205, https://doi.org/10.1016/B978-0-12-816992-6.00006-1.

33. Wang, X.; Li, D.; Zhang, Y.; Wu, S.; Tang, F. Costus root granules improve ulcerative colitis through regulation of TGF- $\beta$ mediation of the PI3K/AKT signaling pathway. Experimental and therapeutic medicine 2018, 15, 4477-4484, https://doi.org/10.3892/etm.2018.5946.

34. El-Far, A.H.; Shaheen, H.M.; Alsenosy, A.W.; El-Sayed, Y.S.; Al Jaouni, S.K.; Mousa, S.A. Costus speciosus: Traditional Uses, Phytochemistry, and Therapeutic Potentials. Pharmacognosy Reviews 2018, 12, https://doi.org/10.4103/phrev.phrev_29_17.

35. Punyarani, K.; Sharma, J.G. Micropropagation of Costus speciosus (Koen.) Sm. using nodal segment culture. Notulae Scientia Biologicae 2010, 2, 58-62, https://doi.org/10.15835/nsb213552.

36. El-Far, A.; Abou-Ghanema, I. Biochemical and hematological evaluation of Costus speciosus as a dietary supplement to Egyptian buffaloes. African Journal of Pharmacy and Pharmacology 2013, 7, 2774-2779, https://doi.org/10.5897/AJPP2013.3519.

37. Rajesh, M.; Harish, M.; Sathyaprakash, R.; Shetty, A.R.; Shivananda, T. Antihyperglycemic activity of the various extracts of Costus speciosus rhizomes. Journal of natural remedies 2009, 9, 235-241.

38. AL-Ameri, N.O.; Azeez, Z.F. Morphological effects of alcoholic extract of Costus speciosus Koen. on Aspergillus sp. that causing pulmonary infections (III). Journal of Natural Sciences Research 2014, 4, 98-101.

39. Nehete, J.; Bhatia, M.; Narkhede, M. In-vitro evaluation of antioxidant activity and phenolic content of Costus speciosus (Koen) JE Sm. Iranian journal of pharmaceutical research: IJPR 2010, 9, 271-277.

40. Rani, A.S.; Sulakshana, G.; Patnaik, S. Costus speciosus, an antidiabetic plant-review. FS J Pharm Res 2012, $1,51-53$.

41. Al-brakati, A.Y.a.A.; Hassan M. Evaluation of the Hepatoprotective Efficacy of Moringa oleifera on TramalInduced Liver Toxicity in Animal Modules. Research Journal of Pharmaceutical, Biological and Chemical Sciences 2016, 7, 1494-1501.

42. Srivastava, S.; Singh, P.; Jha, K.; Mishra, G.; Srivastava, S.; Khosa, R. Anthelmintic activity of aerial parts of Costus speciosus. International Journal of Green Pharmacy (IJGP) 2011, 5, 325-328,

43. Kilian, D.J.; Moreland, F.M.; Benge, M.C.; Legator, M.S.; Whorton, E. A collaborative study to measure interlaboratory variation with the in vivo bone marrow metaphase procedure. In: Handbook of mutagenicity test procedures. Elsevier Amsterdam: 1977; pp. 243-260, https://doi.org/10.1016/00275107(77)90118-X.

44. Ohkawa, H.; Ohishi, N.; Yagi, K. Assay for lipid peroxides in animal tissues by thiobarbituric acid reaction. Analytical biochemistry 1979, 95, 351-358, https://doi.org/10.1016/0003-2697(79)90738-3.

45. Kovárová, H.; Stoklasová, A.; Ledvina, M. Activity of superoxide dismutase isoenzymes in the bone marrow of irradiated rabbits. Sbornik vedeckych praci Lekarske fakulty Karlovy university v Hradci Kralove 1992, 35, 231-240.

46. Aebi, H. Catalase in vitro. Methods in enzymology 1984, 105, 121-126, https://doi.org/10.1016/S00766879(84)05016-3.

47. Ellman, G.L. Tissue sulfhydryl groups. Archives of biochemistry and biophysics 1959, 82, 70-77, https://doi.org/10.1016/0003-9861(59)90090-6.

48. Ramani Vijayan, G.A.; Bashir, K.; Cardosa, M.; Chadha, M.; Chaudakshetrin, P.; Hla, K.M.; Joshi, M.; Javier, F.O.; Kayani, A.G.; Musba, A.T. Tramadol: a valuable treatment for pain in Southeast Asian countries. Journal of pain research 2018, 11, 2567-2575, https://doi.org/10.2147/JPR.S162296. 
49. Skrabalova, J.; Drastichova, Z.; Novotny, J. Morphine as a Potential Oxidative Stress-Causing Agent. Mini Rev Org Chem 2013, 10, 367-372, https://doi.org/10.2174/1570193X113106660031.

50. Deavall, D.G.; Martin, E.A.; Horner, J.M.; Roberts, R. Drug-induced oxidative stress and toxicity. $J$ Toxicol 2012, 2012, 645460-645460, https://doi.org/10.1155/2012/645460.

51. Elmanama, A.A.; Tayyem, N.E.A.; Essawaf, H.N.; Hmaid, I.M. Tramadol-induced liver and kidney toxicity among abusers in Gaza Strip, Palestine. Jordan Journal of Biological Sciences 2015, 8, 133137, https://doi.org/10.12816/0027559.

52. Sayed, H.Y.M.; Zidan, A.H. Histopathological and Biochemical Effects of Acute and Chronic Tramadol Drug Toxicity on Liver, Kidney, and Testicular Function in Adult Male Albino Rats. Journal of Forensic 2016, 1, https://doi.org/10.15406/frcij.2016.02.00060.

53. do Céu Silva, M.; Gaspar, J.; Duarte Silva, I.; Leão, D.; Rueff, J. Mechanisms of induction of chromosomal aberrations by hydroquinone in V79 cells. Mutagenesis 2003, 18, 491-496, https://doi.org/10.1093/mutage/geg029.

54. Moore, R.C. Effects of 1-beta-D-arabinofuranosylcytosine on chromosomes, depending upon the cell cycle stage at the time of exposure. Mutation research 1981, 83, 361-374, https://doi.org/10.1016/00275107(81)90018-X.

55. Febrer, E.; Mestres, M.; Caballin, M.R.; Barrios, L.; Ribas, M.; Gutierrez-Enriquez, S.; Alonso, C.; Ramon y Cajal, T.; Francesc Barquinero, J. Mitotic delay in lymphocytes from BRCA1 heterozygotes unable to reduce the radiation-induced chromosomal damage. DNA repair 2008, 7, 1907-1911, https://doi.org/10.1016/j.dnarep.2008.08.001.

56. Ito, D.; Matsumoto, T. Molecular mechanisms and function of the spindle checkpoint, a guardian of the chromosome stability. Advances in experimental medicine and biology 2010, 676, 15-26, https://doi.org/10.1007/978-1-4419-6199-0_2.

57. de Hondt, H.A.; Fahmy, A.M.; Abdelbaset, S.A. Chromosomal and biochemical studies on the effect of kat extract on laboratory rats. Environmental mutagenesis 1984, 6, 851-860, https://doi.org/10.1002/em.2860060611.

58. Szczepaniak, A.; Fichna, J.; Zielińska, M. Opioids in Cancer Development, Progression and Metastasis: Focus on Colorectal Cancer. Curr Treat Options Oncol 2020, 21, 6-6, https://doi.org/10.1007/s11864019-0699-1.

59. Faraj, S. Genotoxicity of Dactinomycin and Tramadol on Mice Bone Marrow. International Journal of Scientific Engineering and Research 2015, 791, 2347-3878.

60. Wolff, S.; Rodin, B.; Cleaver, J. Sister chromatid exchanges induced by mutagenic carcinogens in normal and xeroderma pigmentosum cells. Nature 1977, 265, 347-349, https://doi.org/10.1038/265347a0.

61. Cavallo, D.; Ursini, C.; Bavazzano, P.; Cassinelli, C.; Frattini, A.; Perniconi, B.; Di Francesco, A.; Ciervo, A.; Rondinone, B.; Iavicoli, S. Sister chromatid exchange and oxidative DNA damage in paving workers exposed to PAHs. Annals of Occupational Hygiene 2006, 50, 211-218, https://doi.org/10.1093/annhyg/mei072.

62. Maleek, M.I.; Safaa, A.; Marwa, M. Genotoxicity of dactinomycin and Tramadol on mice bone marrow. International Journal of Scientific Engineering and Research 2015, 4, 9-14.

63. Alsarra, I.A.; Ahmed, M.O.; Alanazi, F.K.; Eltahir, K.E.; Alsheikh, A.M.; Neau, S.H. Influence of cyclodextrin complexation with NSAIDs on NSAID/cold stress-induced gastric ulceration in rats. International journal of medical sciences 2010, 7, 232-239, https://doi.org/10.7150/ijms.7.232.

64. Kawauchi, S.; Furuya, T.; Ikemoto, K.; Nakao, M.; Yamamoto, S.; Oka, M.; Sasaki, K. DNA copy number aberrations associated with aneuploidy and chromosomal instability in breast cancers. Oncology reports 2010, 24, 875-883, https://doi.org/10.3892/or.2010.875.

65. Sun, T.; Gao, G.-Z.; Li, R.-F.; Li, X.; Li, D.-W.; Wu, S.-S.; Yeo, A.E.; Jin, B. Bone marrow-derived mesenchymal stem cell transplantation ameliorates oxidative stress and restores intestinal mucosal permeability in chemically induced colitis in mice. Am J Transl Res 2015, 7, 891-901.

66. Ahmed, M.A.; Kurkar, A. Effects of opioid (tramadol) treatment on testicular functions in adult male rats: The role of nitric oxide and oxidative stress. Clinical and Experimental Pharmacology and Physiology 2014, 41, 317-323, https://doi.org/10.1111/1440-1681.12213.

67. Smith, H.S. Opioid metabolism. Mayo Clin Proc 2009, 84, 613-624, https://doi.org/10.1016/S00256196(11)60750-7.

68. Plhalova, L.; Sehonova, P.; Blahova, J.; Doubkova, V.; Tichy, F.; Faggio, C.; Berankova, P.; Svobodova, Z. Evaluation of Tramadol Hydrochloride Toxicity to Juvenile Zebrafish-Morphological, Antioxidant and Histological Responses. Applied Sciences 2020, 10, https://doi.org/10.3390/app10072349.

69. Ezejiofor, A.N.; Orisakwe, O.E. The protective effect of Costus afer Ker Gawl aqueous leaf extract on lead-induced reproductive changes in male albino Wistar rats. JBRA assisted reproduction 2019, 23. 